\title{
The puzzling deuteration of methanol in low- to high-mass protostars ${ }^{\star}$
}

\author{
A. Ratajczak, V. Taquet, C. Kahane, C. Ceccarelli, A. Faure, and E. Quirico \\ UJF-Grenoble 1/CNRS, Institut de Planétologie et d'Astrophysique de Grenoble (IPAG) UMR 5274, 38041 Grenoble, France \\ e-mail: afaure@obs.ujf-grenoble.fr
}

Received 23 December 2010 / Accepted 16 February 2011

\begin{abstract}
Context. The current theory of methanol deuteration on interstellar grains predicts that the abundance ratio of the singly deuterated isotopologues $\left[\mathrm{CH}_{2} \mathrm{DOH}\right] /\left[\mathrm{CH}_{3} \mathrm{OD}\right]$ should always be $\sim 3$. In warm regions where grain mantles have sublimated, gaseous methanol is detectable via its rotational transitions. In previous observational studies, the gas-phase $\left[\mathrm{CH}_{2} \mathrm{DOH}\right] /\left[\mathrm{CH}_{3} \mathrm{OD}\right]$ ratio was measured and found to be significantly larger than 3 in low-mass protostars and close to 1 in the Orion IRc2 massive hot core.

Aims. We present new measurements of the gas-phase $\left[\mathrm{CH}_{2} \mathrm{DOH}\right] /\left[\mathrm{CH}_{3} \mathrm{OD}\right]$ ratio in two additional high-mass protostars, as well as in two intermediate-mass protostars, to either confirm or exclude the dependence of this ratio on the mass of the protostar.

Methods. The observations were carried out using the IRAM-30 m telescope. Several rotational lines of each isotopologue were detected toward the intermediate-mass protostars, while only $\mathrm{CH}_{3} \mathrm{OD}$ lines were detected in the massive hot cores. The ratio $\left[\mathrm{CH}_{2} \mathrm{DOH}\right] /\left[\mathrm{CH}_{3} \mathrm{OD}\right]$ (or its upper limit) was computed from both the averaged column densities and directly from line flux ratios.

Results. Our results confirm that the $\left[\mathrm{CH}_{2} \mathrm{DOH}\right] /\left[\mathrm{CH}_{3} \mathrm{OD}\right]$ ratio is substantially lower in massive hot cores than in (low-mass) hotcorinos, by typically one order of magnitude. Furthermore, they suggest that intermediate-mass protostars have similar properties to low-mass protostars.

Conclusions. The measured $\left[\mathrm{CH}_{2} \mathrm{DOH}\right] /\left[\mathrm{CH}_{3} \mathrm{OD}\right]$ ratios are inconsistent with the current theory of methanol deuteration, independently of the mass of the source. While the large ratios measured in low- and intermediate-mass sources can be explained qualitatively by various selective depletion mechanisms, the small ratios $(<2)$ measured toward massive hot cores are puzzling. A revision of the deuterium chemistry in hot cores is suggested.
\end{abstract}

Key words. molecular processes - stars: protostars - ISM: molecules

\section{Introduction}

Since the first detection of a deuterated isotopologue in space (DCN, Jefferts et al. 1973), molecular deuteration has been considered as a powerful diagnostic tool for studying the physical conditions and past history of the interstellar gas (see for example the reviews by Roueff \& Gerin 2003 and Ceccarelli et al. 2007). Among the various molecules with high degrees of deuteration, methanol is a particularly interesting one, for several reasons. First the detection of the (gaseous) triply deuterated methanol with an abundance of a few percent with respect to the hydrogenated counterpart makes it the most deuterium-enriched molecule so far known (Parise et al. 2004). Second, theoretical and experimental studies predict that methanol is formed on the grain surfaces rather than in the gas-phase (Garrod et al. 2006). Thus, the measurements of methanol deuteration permit us to study, almost unambiguously (see below), the process(es) on the grain surfaces. The link with observations is however complicated. This is firstly because there are at least two ways to form methanol on the surfaces: either by addition of hydrogen atoms on iced CO (e.g. Nagaoka et al. 2005) or by the photolysis or radiolysis of an iced mixture of methane, $\mathrm{CO}$, and water (e.g. Hudson \& Moore 1999; Wada et al. 2006). Deuteration is expected to be very different in the two cases and, specifically,

$\star$ Table A.1 is only available in electronic form at http://www. aanda.org much higher in the first case. Secondly, the alteration of the deuteration degree can occur on the grain surfaces via $\mathrm{H} / \mathrm{D}$ atom exchanges both because of thermal activation (Ratajczak et al. 2009) or, again, photolysis (Weber et al. 2009). In addition, when solid methanol sublimates, it can undergo chemical reactions in the gas phase, which may again alter the original deuteration degree set on the grain surfaces (Charnley et al. 1997; Osamura et al. 2004). Despite the complications and thanks to them, deuterated methanol is a tool rich in information.

Previous studies toward low mass protostars have shown that the singly deuterated methanol $\mathrm{CH}_{2} \mathrm{DOH}$ can be almost as abundant as $\mathrm{CH}_{3} \mathrm{OH}$ (e.g. Parise et al. 2006), a property observed in several other deuterated molecules in low mass protostars, although to a lesser extent (Ceccarelli et al. 2007). This large deuteration very likely implies that, in low mass protostars, methanol was formed during the pre-collapse, cold, and dense phase. Surprisingly, however, the other form of singly deuterated methanol, $\mathrm{CH}_{3} \mathrm{OD}$, is much less abundant, by more than a factor of 10 . According to the grain chemistry statistical model of Charnley et al. (1997), if the deuterated isotopologues of methanol are formed by $\mathrm{H} / \mathrm{D}$ atoms addition to $\mathrm{CO}$ on the grain surfaces, the abundance of $\mathrm{CH}_{2} \mathrm{DOH}$ should always be only a factor of $\sim 3$ larger than the $\mathrm{CH}_{3} \mathrm{OD}$ one. To make the situation even more puzzling, the same $\left[\mathrm{CH}_{2} \mathrm{DOH}\right] /\left[\mathrm{CH}_{3} \mathrm{OD}\right]$ ratio is close to 1 in the high-mass protostar Orion IRc2 (Jacq et al. 1993). This difference between high- and low-mass protostars 
might reflect different deuteration degrees and/or ice compositions, as suggested by Ratajczak et al. (2009). On the other hand, no other measurement of the $\left[\mathrm{CH}_{2} \mathrm{DOH}\right] /\left[\mathrm{CH}_{3} \mathrm{OD}\right]$ ratio exists in high-mass protostars other than Orion IRc2, so that the measured low $\left[\mathrm{CH}_{2} \mathrm{DOH}\right] /\left[\mathrm{CH}_{3} \mathrm{OD}\right]$ ratio may be peculiar to this source, itself peculiar in many other aspects.

In this Letter, we present new measurements of the $\left[\mathrm{CH}_{2} \mathrm{DOH}\right] /\left[\mathrm{CH}_{3} \mathrm{OD}\right]$ ratio in two additional high-mass protostars, which confirm the low value measured in Orion IRc2. In addition, we present observations of deuterated methanol in intermediate mass protostars. As shown by Crimier et al. (2010), intermediate mass protostars are in several aspects also intermediate in the characteristics between low- and high-mass protostars. Their case can therefore help us to understand why the $\left[\mathrm{CH}_{2} \mathrm{DOH}\right] /\left[\mathrm{CH}_{3} \mathrm{OD}\right]$ ratio is so different at the two extremes of the mass range.

\section{Observations and data reduction}

The observations were carried out using the IRAM-30 m telescope in June 2010. Two frequency ranges were observed simultaneously with the new broad-band EMIR receivers, one centered at $110.2 \mathrm{GHz}$, the other at $134.0 \mathrm{GHz}$. At these frequencies, the $30 \mathrm{~m}$ telescope HPBW is, respectively, $22^{\prime \prime}$ and $18^{\prime \prime}$ and the main beam efficiency is close to 0.78 . Each receiver was equipped with two channels corresponding to orthogonal linear polarizations and showed image rejections higher than $20 \mathrm{~dB}$ when operating in single sideband mode. The broad-band autocorrelator WILMA, divided into four parts, each providing a spectral resolution of $2 \mathrm{MHz}$ and a frequency coverage of $3.7 \mathrm{GHz}$, was associated with the four channels. In addition, a high resolution autocorrelator, VESPA, was divided into two parts, one centered at $110.2 \mathrm{GHz}$ covering $140 \mathrm{MHz}$ with a spectral resolution of $80 \mathrm{kHz}$, the second centered at $134.0 \mathrm{GHz}$ with a coverage of $290 \mathrm{MHz}$ and a resolution of $310 \mathrm{kHz}$. The system temperatures were between $95 \mathrm{~K}$ and $115 \mathrm{~K}$ at $134 \mathrm{GHz}$ and between $155 \mathrm{~K}$ and $180 \mathrm{~K}$ at $110 \mathrm{GHz}$. Observations were performed in wobbler-switch mode, with a $90^{\prime \prime}$ throw at a rate of $0.5 \mathrm{~Hz}$. The temperature scale was calibrated every $15 \mathrm{~min}$ using two absorbers at different temperatures and the calibration uncertainty $(1 \sigma)$ is about $15 \%$ of the line flux at both frequency ranges. The pointing and focus were checked every two hours on planets and continuum radio sources close to the targets. Effective on-source integration times were $45 \mathrm{~min}$ for G24.78, $140 \mathrm{~min}$ for $\mathrm{OMC} 2$, and $210 \mathrm{~min}$ for CepE and $\mathrm{W} 3(\mathrm{H} 2 \mathrm{O})$, where both polarisation channels were added (after checking that the line intensities were identical).

The deuterated methanol lines detected in the high resolution spectra were fitted with Gaussian profiles using the CLASS tool ${ }^{1}$ and the frequencies given in Parise et al. (2002). For the $\mathrm{CH}_{3} \mathrm{OH}$ lines detected in the broad-band spectra, we used the CASSIS package $^{2}$ and the spectroscopic data from the CDMS database (Müller et al. 2001, 2004, and references therein) to perform the line identification and the Gaussian fit. In both cases, only linear baselines were subtracted from the spectra.

\section{Data analysis}

Table A. 1 presents the results of Gaussian fits to our observations for $\mathrm{CH}_{3} \mathrm{OH}$ and its two isotopologues $\mathrm{CH}_{2} \mathrm{DOH}$ and $\mathrm{CH}_{3} \mathrm{OD}$.

\footnotetext{
${ }^{1}$ http://wWw.iram.fr/IRAMFR/GILDAS

${ }^{2}$ http://cassis.cesr.fr
}
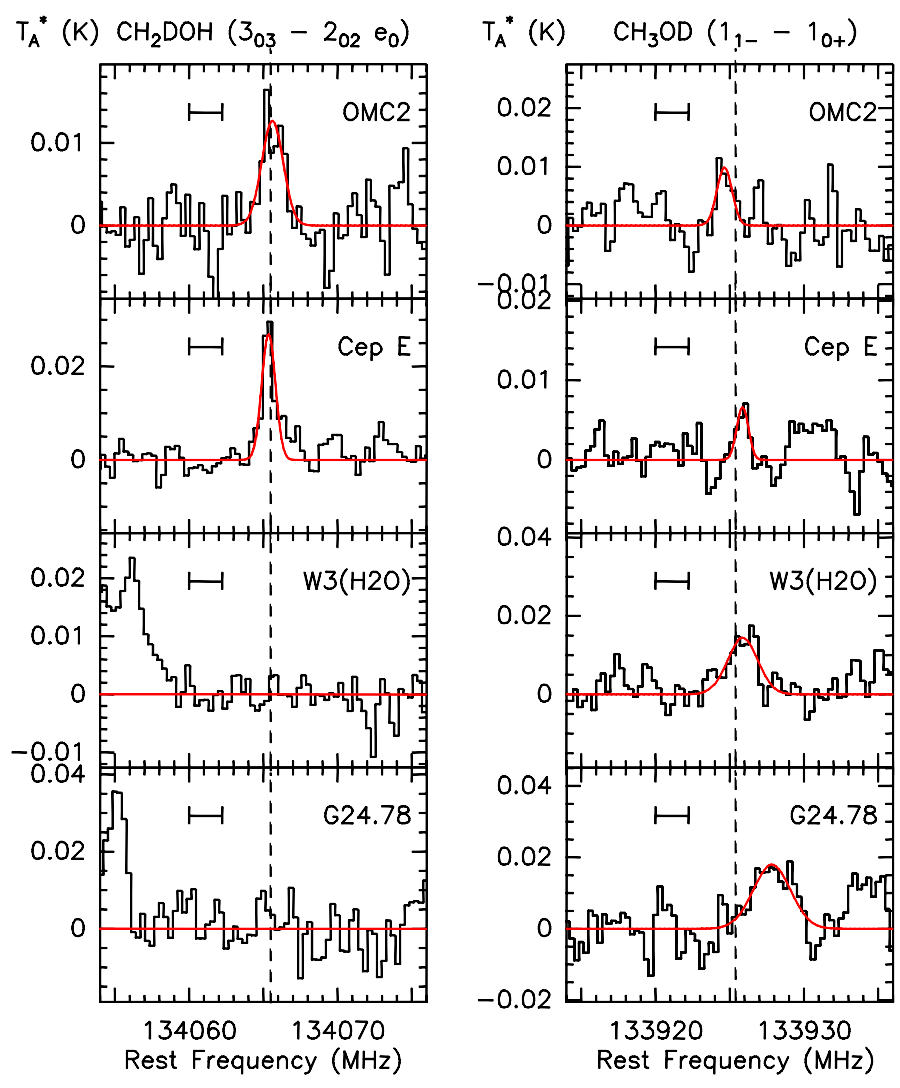

Fig. 1. $\mathrm{CH}_{2} \mathrm{DOH}$ and $\mathrm{CH}_{3} \mathrm{OD}$ spectra towards the four sources. The observed positions and the assumed $v_{\mathrm{LSR}}$ rest velocities are the following: OMC2 FIR4 (05:35:26.7, -05:09:59), $10.5 \mathrm{~km} \mathrm{~s}^{-1}$; CepheusE $(23: 03: 12.7, \quad+61: 42: 27), \quad-11.4 \quad \mathrm{~km} \mathrm{~s}^{-1} ; \mathrm{W} 3\left(\mathrm{H}_{2} \mathrm{O}\right) \quad(02: 27: 04.6$, +61:52:26), -48.0 $\mathrm{km} \mathrm{s}^{-1}$; G24.78+0.08 (18:36:12.6, -07:12:11), $111.0 \mathrm{~km} \mathrm{~s}^{-1}$. The line intensities are expressed in antenna temperature scale. The curves are Gaussian fits to the detected lines and the dashed lines indicate the expected frequencies of the lines. The small horizontal segment has a width of $5 \mathrm{~km} \mathrm{~s}^{-1}$. The broad feature right to the $\mathrm{CH}_{3} \mathrm{OD}$ line in Cep $\mathrm{E}$ includes the $\mathrm{CH}_{2} \mathrm{DOH}$ line $\left(3_{21}-2_{20} \mathrm{e} 1\right)$ at $133930.2 \mathrm{GHz}$. The $\mathrm{CH}_{3} \mathrm{OD}$ line in $\mathrm{G} 24.78+0.08$ appears at a significantly velocity shift so that its identification must be considered as uncertain.

The spectra of the $\mathrm{CH}_{2} \mathrm{DOH} 3_{03}-2_{02} e_{0}$ and the $\mathrm{CH}_{3} \mathrm{OD} 1_{1-}-1_{0+}$ transitions are plotted in Fig. 1.

Assuming that the spatial distribution of both isotopologues is the same in the region probed by the observations, the $\left[\mathrm{CH}_{2} \mathrm{DOH}\right] /\left[\mathrm{CH}_{3} \mathrm{OD}\right]$ abundance ratio is simply equal to the column density ratio. In addition, if the lines are optically thin and the populations of all molecular energy levels in thermodynamical equilibrium are at the same rotational temperature $T_{\text {rot }}$, then for each isotopologue $(i)$ the total column density $N_{i}$ can be derived from the line flux $W_{i}$ of any of its transitions by the relation:

$N_{i}=\left(\frac{3 k_{\mathrm{b}} W_{i}}{8 \pi^{3} v_{i}\left(\mu^{2} S\right)_{i}}\right) Z_{i}\left(T_{\text {rot }}\right) \exp \left[\frac{E_{\mathrm{u}, i}}{k_{\mathrm{b}} T_{\text {rot }}}\right]$,

where $Z_{i}\left(T_{\text {rot }}\right)$ is the partition function and $v_{i}$ the frequency of the transition from the upper level of energy $E_{\mathrm{u}, i}$, corresponding to the effective line strength $\left(\mu^{2} S\right)_{i}$. Thus, the $\left[\mathrm{CH}_{2} \mathrm{DOH}\right] /\left[\mathrm{CH}_{3} \mathrm{OD}\right]$ ratio can be derived directly from any line flux ratio using

$\frac{N_{1}}{N_{2}}=\left(\frac{W_{1}}{W_{2}}\right) \frac{Z_{1}\left(T_{\text {rot }}\right) v_{2}\left(\mu^{2} S\right)_{2}}{Z_{2}\left(T_{\text {rot }}\right) v_{1}\left(\mu^{2} S\right)_{1}} \exp \left[\frac{E_{\mathrm{u}, 1}-E_{\mathrm{u}, 2}}{k_{\mathrm{b}} T_{\text {rot }}}\right]$, 
where Eqs. (1) and (2) refer respectively to $\mathrm{CH}_{2} \mathrm{DOH}$ and $\mathrm{CH}_{3} \mathrm{OD}$. The rotational partition functions were computed within the rigid-rotor approximation, assuming that the rotational temperature is much higher than the largest rotational constant (here $\left.A\left(\mathrm{CH}_{3} \mathrm{OH}\right) \sim 6 \mathrm{~K}\right)$. The corresponding expression for $\mathrm{CH}_{3} \mathrm{OH}$ and $\mathrm{CH}_{3} \mathrm{OD}$, neglecting the energy difference between the $A$ and $E$ symmetry species, is simply twice the normal asymmetric rotor function

$Z(T)=2 \sqrt{\frac{\pi}{A B C}\left(\frac{k_{\mathrm{b}} T}{h}\right)^{3}}$.

We thus obtain $Z(T)=1.23 T^{3 / 2}$ for $\mathrm{CH}_{3} \mathrm{OH}$ and $Z(T)=$ $1.42 T^{3 / 2}$ for $\mathrm{CH}_{3} \mathrm{OD}$. In the case of $\mathrm{CH}_{2} \mathrm{DOH}$, the energy difference between the $e_{0}, e_{1}$, and $o_{1}$ symmetry species cannot be neglected and the partition function is given by (Parise 2004):

$Z(T)=0.75 T^{3 / 2}[1+\exp (-13.4 / T)+\exp (-18.3 / T)]$.

Thus, the estimate of the abundance ratio depends on the assumed rotational temperature. In practice, however, this ratio was found to be essentially insensitive to rotational temperatures in the range $20-220 \mathrm{~K}$. As the number of detected lines for the deuterated species is too small to get a reliable estimate of $T_{\text {rot }}$ using the rotational diagram method, the rotational temperature was derived from the lines of the main isotopologue $\mathrm{CH}_{3} \mathrm{OH}$, assuming that the rotational temperature is similar for all three isotopologues. For each source, the rotational temperature and the $\mathrm{CH}_{3} \mathrm{OH}$ column density are reported in Table 1 .

Once the rotational temperature of methanol isotopologues is known, the $\left[\mathrm{CH}_{2} \mathrm{DOH}\right] /\left[\mathrm{CH}_{3} \mathrm{OD}\right]$ ratio can be computed via two methods: $i$ ) total column densities of $\mathrm{CH}_{2} \mathrm{DOH}$ and $\mathrm{CH}_{3} \mathrm{OD}$ can be estimated from each of the detected lines using Eq. (1). The ratio of the averaged column densities provides a first measure of the $\left[\mathrm{CH}_{2} \mathrm{DOH}\right] /\left[\mathrm{CH}_{3} \mathrm{OD}\right]$ ratio. This method however requires us to take into account the calibration uncertainty in each line, since data coming from both frequency ranges are used. The results are shown in Col. 7 of Table 1. ii) Using Eq. (2), we can obtain as many abundance ratios as there are pairs formed with $\mathrm{CH}_{2} \mathrm{DOH}$ and $\mathrm{CH}_{3} \mathrm{OD}$ lines. However, some of these pairs allow us to achieve a better precision than others. They have to satisfy two criteria: the upper levels must be close in energy and the lines must belong to the same frequency band to be able to ignore the calibration uncertainty. In practice, in our data, a single pair of lines satisfies both criteria and the ratios derived by this method are given in column 6 of Table 1 . It is observed that both methods give essentially the same result, within the estimated uncertainties, suggesting the reliability of the derived ratios. These results clearly show that in the two observed intermediate-mass protostars, the $\left[\mathrm{CH}_{2} \mathrm{DOH}\right] /\left[\mathrm{CH}_{3} \mathrm{OD}\right]$ ratio is larger than 3 and much higher than the ratios in high-mass protostars. For these latter, only upper limits of the ratio were derived because no line of $\mathrm{CH}_{2} \mathrm{DOH}$ was detected. Implications of these results are discussed in detail below.

\section{Discussion and conclusions}

In Fig. 2, we have plotted the $\left[\mathrm{CH}_{2} \mathrm{DOH}\right] /\left[\mathrm{CH}_{3} \mathrm{OD}\right]$ ratio as a function of the luminosity of the protostars for all the sources (except G24.78+0.08) where this ratio has been measured so far. In addition to the present observations, we have thus included a sample of low-mass protostars (Parise et al. 2006), as well as the hot-core Orion IRc2 (Jacq et al. 1993). Our results confirm that the $\left[\mathrm{CH}_{2} \mathrm{DOH}\right] /\left[\mathrm{CH}_{3} \mathrm{OD}\right]$ ratio is substantially

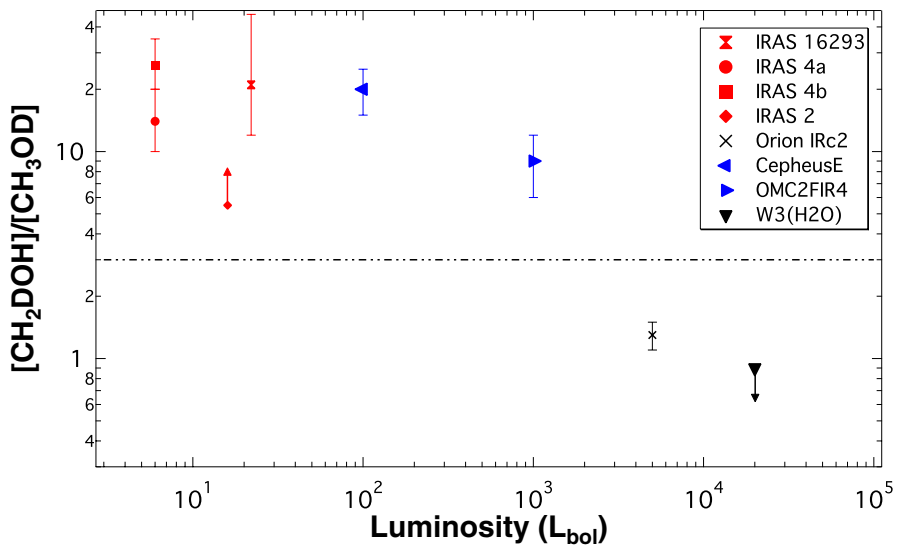

Fig. 2. $\left[\mathrm{CH}_{2} \mathrm{DOH}\right] /\left[\mathrm{CH}_{3} \mathrm{OD}\right]$ ratio as a function of the protostar luminosity. Low-mass data (IRAS 16293, IRAS 4a, IRAS 4b and IRAS 2) were taken from Parise et al. (2006), while the data for Orion IRc2 is from Jacq et al. (1993). The upper limit reported in Table 1 for G24.78+0.08 is not plotted because of the uncertain identification of the $\mathrm{CH}_{3} \mathrm{OD}$ line at $133.9254 \mathrm{GHz}$. The horizontal dashed line refers to the value predicted by grain chemistry models (Charnley et al. 1997).

lower in massive hot cores than in (low-mass) hot-corinos, by typically one order of magnitude. Furthermore, they suggest that intermediate-mass protostars have similar properties to lowmass protostars. We have also found that in all sources, the observed $\left[\mathrm{CH}_{2} \mathrm{DOH}\right] /\left[\mathrm{CH}_{3} \mathrm{OD}\right]$ ratio significantly differs from the value of 3 predicted by the grain chemistry models of Charnley et al. (1997) and Osamura et al. (2004). In low- and intermediate- mass protostars, this ratio is much greater than 3 , while in high-mass protostars it is significantly lower. As a result, whatever the mass of the source, the observed gas-phase $\left[\mathrm{CH}_{2} \mathrm{DOH}\right] /\left[\mathrm{CH}_{3} \mathrm{OD}\right]$ ratio is inconsistent with the current theory of methanol deuteration in the grain mantles, that is via additions of H/D atoms on solid CO. Alternative or additional processes in solid-state and/or in the post-evaporative gas-phase must be at play in the hot cores/corinos. We now discuss the different possibilites based on theoretical and laboratory works.

For low- and intermediate-mass protostars, various mechanisms have been suggested to explain the much lower abundance of $\mathrm{CH}_{3} \mathrm{OD}$ compared to $\mathrm{CH}_{2} \mathrm{DOH}$. First, $\mathrm{CH}_{3} \mathrm{OD}$ could be selectively destroyed in the gas-phase via protonation reactions because the dissociative recombination (DR) of $\mathrm{CH}_{2} \mathrm{DOH}^{+}$ reforms $\mathrm{CH}_{2} \mathrm{DOH}$, while the DR of $\mathrm{CH}_{3} \mathrm{ODH}^{+}$leads to both $\mathrm{CH}_{3} \mathrm{OD}$ and $\mathrm{CH}_{3} \mathrm{OH}$ (Charnley et al. 1997; Osamura et al. 2004). Second, laboratory experiments have suggested that $H / D$ exchange reactions in solid state might contribute to reducing the $\mathrm{CH}_{3} \mathrm{OD}$ abundance. Thus, in the experiment of Nagaoka et al. (2005), the deuterium enrichment was found to proceed via H/D substitution in solid $\mathrm{CH}_{3} \mathrm{OH}$ leading to the formation of methyldeuterated methanol isotopologues, but no $\mathrm{CH}_{3} \mathrm{OD}$. An alternative solid-state depletion mechanism was proposed by Ratajczak et al. (2009): in their experiment, rapid H/D exchanges between $\mathrm{CD}_{3} \mathrm{OD}$ and $\mathrm{H}_{2} \mathrm{O}$ ices were found to occur at $T \sim 120 \mathrm{~K}$ on the hydroxyl (-OD) functional group of methanol, resulting in $\mathrm{CD}_{3} \mathrm{OH}$ and $\mathrm{HDO}$ molecules.

All the previous mechanisms can thus qualitatively explain a much lower abundance of $\mathrm{CH}_{3} \mathrm{OD}$ compared to $\mathrm{CH}_{2} \mathrm{DOH}$, as observed in low- and intermediate-mass protostars. The reverse behavior, as observed unambiguously in $\mathrm{W} 3\left(\mathrm{H}_{2} \mathrm{O}\right)$ and Orion IRc2, is more difficult to understand. We note, however, that the gas temperature in massive hot cores may be significantly higher than in low- and intermediate-mass protostars, as 
Table 1. Isotopologue ratios $\left[\mathrm{CH}_{2} \mathrm{DOH}\right] /\left[\mathrm{CH}_{3} \mathrm{OD}\right]$ in low-, intermediate- and high-mass protostars, luminosities and distances of the sources, column densities $\left(\times 10^{15} \mathrm{~cm}^{-2}\right)$ and rotational temperatures of $\mathrm{CH}_{3} \mathrm{OH}$.

\begin{tabular}{|c|c|c|c|c|c|c|}
\hline Source & Luminosity $\left(L_{\odot}\right)$ & Distance $(\mathrm{pc})$ & $N_{\text {tot }}\left(\mathrm{CH}_{3} \mathrm{OH}\right)$ & $T_{\text {rot }}\left(\mathrm{CH}_{3} \mathrm{OH}\right)(\mathrm{K})$ & {$\left[\mathrm{CH}_{2} \mathrm{DOH}\right] /\left[\mathrm{CH}_{3} \mathrm{OD}\right]$} & $\left\langle\left[\mathrm{CH}_{2} \mathrm{DOH}\right]\right\rangle /\left\langle\left[\mathrm{CH}_{3} \mathrm{OD}\right]\right\rangle$ \\
\hline IRAS 4A ${ }^{a}$ & 6 & $2.2 \times 10^{2}$ & $0.7 \pm 0.1$ & $38 \pm 3$ & & $14^{+6}$ \\
\hline $\operatorname{IRAS} 4 \mathrm{~B}^{a}$ & 6 & $2.2 \times 10^{2}$ & $0.8 \pm 0.3$ & $85 \pm 17$ & & $26_{-6}^{+9}$ \\
\hline $\operatorname{IRAS} 2^{a}$ & 16 & $2.2 \times 10^{2}$ & $1.1 \pm 0.4$ & $207 \pm 48$ & & $>5.5$ \\
\hline IRAS $16293^{a}$ & 27 & $1.6 \times 10^{2}$ & $3.5 \pm 0.4$ & $85 \pm 6$ & & $21_{-9}^{+25}$ \\
\hline Cepheus $\mathrm{E}^{b}$ & $1 \times 10^{2}$ & $7.3 \times 10^{2}$ & $0.5_{-03}^{+0.8}$ & $44 \pm 31$ & $20 \pm 5$ & $18 \pm 5$ \\
\hline OMC2FIR $4^{b}$ & $1 \times 10^{3}$ & $4.4 \times 10^{2}$ & $1.4_{-0.8}^{+2.3}$ & $48 \pm 24$ & $9 \pm 3$ & $8 \pm 7$ \\
\hline Orion $\operatorname{IRc} 2^{c}$ & $5 \times 10^{3}$ & $4.5 \times 10^{2}$ & $84 \pm 8.0$ & $112 \pm 11$ & & $1.1-1.5$ \\
\hline $\mathrm{W} 3(\mathrm{H} 2 \mathrm{O})^{d}$ & $2 \times 10^{4}$ & $2 \times 10^{3}$ & $13_{-2}^{+3}$ & $133 \pm 17$ & $<0.9$ & \\
\hline $\mathrm{G} 24.78+0.08^{e}$ & $\leq 7 \times 10^{4}$ & $7.7 \times 10^{3}$ & $9.3_{-4}^{+7}$ & $113 \pm 44$ & $<1.4^{*}$ & \\
\hline
\end{tabular}

Notes. The column $\left[\mathrm{CH}_{2} \mathrm{DOH}\right] /\left[\mathrm{CH}_{3} \mathrm{OD}\right]$ contains abundance ratios derived from the line pair $134.0655 \mathrm{GHz}$ (for $\mathrm{CH}_{2} \mathrm{DOH}$ ) and $133.9254 \mathrm{GHz}$ (for $\mathrm{CH}_{3} \mathrm{OD}$ ), which shows similar $E_{\text {up }}\left(\Delta E_{\text {up }} \sim 4.2 \mathrm{~K}\right.$ ); the column $\left.\left\langle\left[\mathrm{CH}_{2} \mathrm{DOH}\right]\right\rangle /\left\langle\left[\mathrm{CH}_{3} \mathrm{OD}\right]\right\rangle\right)$ contains ratios derived from averaged column densities (see text). Data for low-mass protostars (IRAS 16293, IRAS 4a, IRAS 4b and IRAS 2) and Orion IRc2 were taken respectively from Parise et al. (2002, 2006) and Jacq et al. (1993), and references therein. The asterisk refers the uncertain identification of the $\mathrm{CH}_{3} \mathrm{OD}$ line (133.9254 GHz) in $\mathrm{G} 24.78+0.08$.

References. For luminosities and distances: ${ }^{(a)}$ Parise et al. (2006); ${ }^{(b)}$ Crimier et al. (2009, 2010); ${ }^{(c)}$ Robberto et al. (2005); ${ }^{(d)}$ Bisschop et al. (2007); ${ }^{(e)}$ Moscadelli et al. (2007).

suggested for example by the $\mathrm{CH}_{3} \mathrm{OH}$ rotational temperatures reported in Table 1 (with the exception of the value measured in IRAS 2). Temperature effects might thus explain the difference in the measured $\left[\mathrm{CH}_{2} \mathrm{DOH}\right] /\left[\mathrm{CH}_{3} \mathrm{OD}\right]$ ratios. Following the pioneering work of Charnley et al. (1997), Osamura et al. (2004) investigated the impact of increasing the gas temperature from 50 to $100 \mathrm{~K}$, using a hot core chemistry network. The $\left[\mathrm{CH}_{2} \mathrm{DOH}\right] /\left[\mathrm{CH}_{3} \mathrm{OD}\right]$ ratio was found to decrease from greater than 3 at $50 \mathrm{~K}$ to $\sim 1$ at $100 \mathrm{~K}$. This effect was attributed to the reaction between $\mathrm{CH}_{3} \mathrm{OH}$ and $\mathrm{H}_{2} \mathrm{DO}^{+}$(which is the major deuteron donor at $100 \mathrm{~K}$ )

$$
\mathrm{H}_{2} \mathrm{DO}^{+}+\mathrm{CH}_{3} \mathrm{OH} \rightarrow \mathrm{CH}_{3} \mathrm{OHD}^{+}+\mathrm{H}_{2} \mathrm{O},
$$

followed by dissociative recombination. However, an unrealistically large initial abundance ratio $[\mathrm{HDO}] /\left[\mathrm{H}_{2} \mathrm{O}\right] \sim 0.1$ was necessary to decrease the $\left[\mathrm{CH}_{2} \mathrm{DOH}\right] /\left[\mathrm{CH}_{3} \mathrm{OD}\right]$ ratio below 3 . Isomerization processes were finally proposed by Charnley et al. (1997) to explain the finding that $\left[\mathrm{CH}_{2} \mathrm{DOH}\right] \sim\left[\mathrm{CH}_{3} \mathrm{OD}\right]$ in Orion IRc2. The quantum calculations of Osamura et al. (2004) demonstrated, however, that internal rearrangements of energized methanol (in the neutral, ionized, or protonated forms) cannot occur efficiently.

We are thus compelled to conclude that the deuteration of methanol in massive hot cores, where the abundance of $\mathrm{CH}_{2} \mathrm{DOH}$ is at most similar to that of $\mathrm{CH}_{3} \mathrm{OD}$, remains enigmatic. It is possibly related to the lower deuterium enrichment of massive protostars compared to low-mass sources (Ceccarelli et al. 2007). We also note that since the distances of the high-mass protostars are significantly larger than those of low- and intermediate-mass sources, the region probed by the observations is much larger in the high-mass objects. This may affect the measurements of the $\left[\mathrm{CH}_{2} \mathrm{DOH}\right] /\left[\mathrm{CH}_{3} \mathrm{OD}\right]$ ratio if the (large-scale) spatial distribution of both isotopologues is different. In any case, additional laboratory and theoretical studies are needed, in particular on $\mathrm{H} / \mathrm{D}$ exchange processes in ices. A revision of the deuterium chemistry in hot cores also seems necessary. In this context, we note that Thi et al. (2010) demonstrated that a high $[\mathrm{HDO}] /\left[\mathrm{H}_{2} \mathrm{O}\right]$ ratio $\left(>10^{-2}\right)$ can be obtained in dense $\left(n_{\mathrm{H}}>10^{6} \mathrm{~cm}^{3}\right)$ and warm gas $(T=100-1000 \mathrm{~K})$ owing to photodissociation and neutral-neutral reactions. In addition to modeling efforts, new observations are also crucial to assessing whether the methanol deuteration is peculiar or whether a similar selective deuteration affects other interstellar species with various functional groups, e.g. $\mathrm{HCOOCH}_{3}, \mathrm{HCONH}_{2}$, and $\mathrm{CH}_{3} \mathrm{NH}_{2}$. The detection of new multiply deuterated species (e.g. $\mathrm{CH}_{2}$ DOD) is also fundamental to helping us to discriminate between the different classes of fractionation/depletion processes.

Acknowledgements. We are deeply thankful to the IRAM staff for assistance during remote observations at the IRAM-30 m telescope. We thank an anonymous referee for constructive comments, which have contributed to improve this manuscript. This work has been supported by l'Agence Nationale pour la Recherche (ANR), France (contract ANR-08-BLAN-022).

\section{References}

Bisschop, S. E., Jørgensen, J. K., van Dishoeck, E. F., \& de Wachter, E. B. M 2007, A\&A, 465, 913

Ceccarelli, C., Caselli, P., Herbst, E., Tielens, A. G. G. M., \& Caux, E. 2007, Protostars and Planets V, 47

Charnley, S. B., Tielens, A. G. G. M., \& Rodgers, S. D. 1997, ApJ, 482, L203

Crimier, N., Ceccarelli, C., Lefloch, B., \& Faure, A. 2009, A\&A, 506, 1229

Crimier, N., Ceccarelli, C., Alonso-Albi, T., et al. 2010, A\&A, 516, A102

Garrod, R., Park, I. H., Caselli, P., \& Herbst, E. 2006, Faraday Discussions, 133, 51

Hudson, R. L., \& Moore, M. H. 1999, Icarus, 140, 451

Jacq, T., Walmsley, C. M., Mauersberger, R., et al. 1993, A\&A, 271, 276 Jefferts, K. B., Penzias, A. A., \& Wilson, R. W. 1973, ApJ, 179, L57

Moscadelli, L., Goddi, C., Cesaroni, R., Beltrán, M. T., \& Furuya, R. S. 2007, A\&A, 472, 867

Müller, H. S. P., Thorwirth, S., Roth, D. A., \& Winnewisser, G. 2001, A\&A, 370, L49

Müller, H. S. P., Menten, K. M., \& Mäder, H. 2004, A\&A, 428, 1019

Nagaoka, A., Watanabe, N., \& Kouchi, A. 2005, ApJ, 624, L29

Osamura, Y., Roberts, H., \& Herbst, E. 2004, A\&A, 421, 1101

Parise, B. 2004, PhD Thesis, Université Toulouse III, France

Parise, B., Ceccarelli, C., Tielens, A. G. G. M., et al. 2002, A\&A, 393, L49

Parise, B., Castets, A., Herbst, E., et al. 2004, A\&A, 416, 159

Parise, B., Ceccarelli, C., Tielens, A. G. G. M., et al. 2006, A\&A, 453, 949

Ratajczak, A., Quirico, E., Faure, A., Schmitt, B., \& Ceccarelli, C. 2009, A\&A, 496, L21

Robberto, M., Beckwith, S. V. W., Panagia, N., et al. 2005, AJ, 129, 1534

Roueff, E., \& Gerin, M. 2003, Space Sci. Rev., 106, 61

Thi, W., Woitke, P., \& Kamp, I. 2010, MNRAS, 407, 232

Wada, A., Mochizuki, N., \& Hiraoka, K. 2006, ApJ, 644, 300

Weber, A. S., Hodyss, R., Johnson, P. V., Willacy, K., \& Kanik, I. 2009, ApJ, 703, 1030

Page 5 is available in the electronic edition of the journal at http://www . aanda. org 
A. Ratajczak et al.: The puzzling deuteration of methanol in protostars

Table A.1. Parameters of the observed $\mathrm{CH}_{3} \mathrm{OH}, \mathrm{CH}_{2} \mathrm{DOH}$, and $\mathrm{CH}_{3} \mathrm{OD}$ transitions.

\begin{tabular}{|c|c|c|c|c|c|c|c|}
\hline Transition & $\begin{array}{l}\text { Frequency } \\
(\mathrm{GHz})\end{array}$ & $\begin{array}{c}\text { Spectroscopic } \\
\text { parameter } \mu^{2} S\left(\text { Deb }^{2}\right)\end{array}$ & $\begin{array}{c}E_{\mathrm{up}} \\
\left(\mathrm{cm}^{-1}\right)\end{array}$ & OMC2FIR4 & CepheusE & $\mathrm{mb} \mathrm{d} v 3\left(\mathrm{H}_{2} \mathrm{O}\right)$ & $\mathrm{G} 24.78+0.08$ \\
\hline $\mathrm{CH}_{3} \mathrm{OH}$ & & & & \multicolumn{4}{|c|}{$\mathrm{K} \mathrm{km} \mathrm{s}^{-1}$} \\
\hline $0_{(+0), 0}-1_{(-1), 1} \mathrm{E}$ & 108.8939 & 1.0 & 9.03 & $1.43 \pm 0.01$ & $0.49 \pm 0.01$ & $4.68 \pm 0.03$ & $9.45 \pm 0.02$ \\
\hline $14_{(+5), 10}-15_{(+4), 11} \mathrm{E}$ & 109.1387 & 3.4 & 264 & $(0.04)$ & $(0.03)$ & $1.09 \pm 0.03$ & $0.82 \pm 0.02$ \\
\hline $16_{(-2), 15}-16_{(+1), 15} \mathrm{E}$ & 109.1531 & 3.7 & 238 & $(0.04)$ & $(0.03)$ & $0.92 \pm 0.03$ & $0.77 \pm 0.03$ \\
\hline $7_{2,5}-8_{1,8} \mathrm{~A}$ & 111.2896 & 2.3 & 71.6 & $0.25 \pm 0.01$ & $(0.03)$ & $3.97 \pm 0.03$ & $2.16 \pm 0.04$ \\
\hline $6_{2,5}-7_{1,6} \mathrm{~A}$ & 132.6219 & 2.0 & 59.6 & $0.48 \pm 0.02$ & $0.07 \pm 0.01$ & $6.80 \pm 0.19$ & $2.54 \pm 0.05$ \\
\hline $6_{(-1), 6}-5_{(+0), 5} \mathrm{E}$ & 132.8907 & 3.7 & 37.5 & $11.30 \pm 0.04$ & $2.81 \pm 0.01$ & $11.09 \pm 0.10$ & $21.03 \pm 0.04$ \\
\hline $5_{(-2), 4}-6_{(-1), 6} E$ & 133.6055 & 1.6 & 42.4 & $0.62 \pm 0.03$ & $(0.03)$ & $4.77 \pm 0.03$ & $2.58 \pm 0.02$ \\
\hline $12_{(-3), 10}-13_{(-2), 12} \mathrm{E}$ & 134.2311 & 3.9 & 170 & $(0.03)$ & $0.09 \pm 0.01$ & $3.61 \pm 0.03$ & $1.50 \pm 0.02$ \\
\hline $8_{2,7}-7_{3,4} \mathrm{~A}$ & 134.8970 & 1.8 & 84.1 & $0.93 \pm 0.01$ & $0.21 \pm 0.01$ & $4.55 \pm 0.04$ & $2.69 \pm 0.03$ \\
\hline $8_{2,6}-7_{3,5} \mathrm{~A}$ & 135.3768 & 1.8 & 84.1 & $0.33 \pm 0.01$ & $(0.03)$ & $4.14 \pm 0.07$ & $2.20 \pm 0.02$ \\
\hline $\mathrm{CH}_{2} \mathrm{DOH}$ & & & & \multicolumn{4}{|c|}{$\mathrm{mK} \mathrm{km} \mathrm{s}{ }^{-1}$} \\
\hline $99_{18}-9_{09}$ o1 & 110.1054 & 3.3 & 83.4 & (32) & $(46)$ & (73) & (103) \\
\hline $3_{03}-2_{02}$ e1 & 133.8473 & 1.1 & 18.3 & $24 \pm 9$ & (35) & (90) & (95) \\
\hline $3_{03}-2_{02}$ o1 & 133.8729 & 1.1 & 21.7 & $(27)$ & $35 \pm 7$ & (25) & (41) \\
\hline $3_{22}-2_{21}$ o1 & 133.8818 & 0.6 & 33.6 & (27) & $(25)$ & (29) & (57) \\
\hline $3_{22}-2_{21}$ e1 & 133.8929 & 0.6 & 27.4 & (27) & (25) & (29) & (57) \\
\hline $3_{21}-2_{20}$ o1 & 133.8974 & 0.6 & 33.6 & $41 \pm 8$ & (24) & (29) & (57) \\
\hline $3_{21}-2_{20} \mathrm{e} 1$ & 133.9302 & 0.6 & 27.4 & $(28)$ & $37 \pm 6$ & (37) & (48) \\
\hline $3_{03}-2_{02} \mathrm{e} 0$ & 134.0655 & 1.2 & 8.90 & $66 \pm 7$ & $89 \pm 4$ & (27) & (49) \\
\hline $3_{22}-2_{21} \mathrm{e} 0$ & 134.1124 & 0.7 & 20.2 & $(28)$ & (19) & (24) & (54) \\
\hline $3_{21}-2_{20} \mathrm{e} 0$ & 134.1854 & 0.7 & 20.2 & $25 \pm 9$ & (29) & (72) & (69) \\
\hline $\mathrm{CH}_{3} \mathrm{OD}$ & & & & \multicolumn{4}{|c|}{$\mathrm{mK} \mathrm{km} \mathrm{s}^{-1}$} \\
\hline $1_{1}-1_{0}$ & 110.1889 & 1.6 & 7.8 & (40) & (40) & (40) & (94) \\
\hline $2_{1}-2_{0}$ & 110.2626 & 2.7 & 10.8 & $57 \pm 11$ & (45) & $93 \pm 18$ & (95) \\
\hline $3_{1}-3_{0}$ & 110.4758 & 3.8 & 15.4 & $(55)$ & (43) & $(67)$ & (108) \\
\hline $1_{1-}-1_{0+}$ & 133.9254 & 3.2 & 6.00 & $28 \pm 6$ & $17 \pm 4$ & $116 \pm 12$ & $141 \pm 16^{*}$ \\
\hline
\end{tabular}

Notes. Fluxes are expressed in main-beam temperature unit. Upper limits (in parentheses) are given at $3 \sigma$ and include both statistical and calibration uncertainties. In contrast, for the detected lines, only $1 \sigma$ statistical uncertainties are given; total uncertainties are given by the quadratic sum of these statistical uncertainties and of $15 \%$ calibration uncertainties. According to the detected $\mathrm{CH}_{3} \mathrm{OH}$ lines, upper limits for both isotopologues were estimated using linewidths of $5 \mathrm{~km} \mathrm{~s}^{-1}$, except for low resolution spectra (velocity resolution of $\sim 5 \mathrm{~km} \mathrm{~s}^{-1}$ ) where linewidths of $9 \mathrm{~km} \mathrm{~s}^{-1}$ were assumed. We have also checked that the relative intens ities of the detected lines and the upper limits on the other lines from $\mathrm{CH}_{2} \mathrm{DOH}$ and $\mathrm{CH}_{3} \mathrm{OD}$ are consistent with predictions at local thermodynamic equilibrium to within a factor two. The asterisk denotes the uncertain identification of the $\mathrm{CH}_{3} \mathrm{OD}$ line $(133.9254 \mathrm{GHz})$ in $\mathrm{G} 24.78+0.08$. 